\title{
Evolution of Specialization of Cassida rubiginosa on Cirsium arvense (Compositae, Cardueae)
}

\author{
Michael G. Cripps ${ }^{1 *}$, Sarah D. Jackman', Cristina Roquet², Chikako van Koten', \\ Michael Rostás ${ }^{3}$, Graeme W. Bourdôt ${ }^{1}$ and Alfonso Susanna ${ }^{4}$
}

\begin{abstract}
${ }^{1}$ AgResearch Ltd., Lincoln, New Zealand, ${ }^{2}$ Laboratoire d'Écologie Alpine, Centre National de la Recherche Scientifique, Université Grenoble Alpes, Grenoble, France, ${ }^{3}$ Bio-Protection Research Centre, University of Lincoln, Lincoln, New Zealand, ${ }^{4}$ Institut Botànic de Barcelona - Consejo Superior de Investigaciones Cientificas - Institut de Cultura de Barcelona, Barcelona, Spain
\end{abstract}

OPEN ACCESS

Edited by:

María Rosa Mosquera-Losada

University of Santiago

de Compostela, Spain

Reviewed by:

Carla Pinheiro,

Faculdade de Ciências e Tecnologia da Universidade Nova de Lisboa,

Portugal

Karl Kunert,

University of Pretoria, South Africa Adalbert Balog,

Sapientia Hungarian University

of Transylvania, Romania

*Correspondence: Michael G. Cripps

mike.cripps@agresearch.co.nz

Specialty section:

This article was submitted to Agroecology and Land Use Systems,

a section of the journal

Frontiers in Plant Science

Received: 25 February 2016 Accepted: 08 August 2016 Published: 23 August 2016

Citation:

Cripps MG, Jackman SD, Roquet C, van Koten $C$, Rostás $M$,

Bourdôt GW and Susanna A (2016) Evolution of Specialization of Cassida rubiginosa on Cirsium arvense

(Compositae, Cardueae).

Front. Plant Sci. 7:1261.

doi: 10.3389/fpls.2016.01261
The majority of herbivorous insects are specialized feeders restricted to a plant family, genus, or species. The evolution of specialized insect-plant interactions is generally considered to be a result of trade-offs in fitness between possible hosts. Through the course of natural selection, host plants that maximize insect fitness should result in optimal, specialized, insect-plant associations. However, the extent to which insects are tracking plant phylogeny or key plant traits that act as herbivore resistance or acceptance characters is uncertain. Thus, with regard to the evolution of host plant specialization, we tested if insect performance is explained by phylogenetic relatedness of potential host plants, or key plant traits that are not phylogenetically related. We tested the survival (naive first instar to adult) of the oligophagous leaf-feeding beetle, Cassida rubiginosa, on 16 selected representatives of the Cardueae tribe (thistles and knapweeds), including some of the worst weeds in temperate grasslands of the world in terms of the economic impacts caused by lost productivity. Leaf traits (specific leaf area, leaf pubescence, flavonoid concentration, carbon and nitrogen content) were measured as explanatory variables and tested in relation to survival of the beetle, and the phylogenetic signal of the traits were examined. The survival of $C$. rubiginosa decreased with increasing phylogenetic distance from the known primary host plant, $C$. arvense, suggesting that specialization is a conserved character, and that insect host range, to a large degree is constrained by evolutionary history. The only trait measured that clearly offered some explanatory value for the survival of $C$. rubiginosa was specific leaf area. This trait was not phylogenetically dependant, and when combined with phylogenetic distance from $C$. arvense gave the best model explaining $C$. rubiginosa survival. We conclude that the specialization of the beetle is explained by a combination of adaptation to an optimal host plant over evolutionary time, and key plant traits such as specific leaf area that can restrict or broaden host utilization within the Cardueae lineage. The phylogenetic pattern of $C$. rubiginosa fitness will aid in predicting the ability of this biocontrol agent to control multiple Cardueae weeds.

Keywords: Cardueae, thistles, weeds, biological control, Cassida rubiginosa, Cirsium arvense, host specificity 


\section{INTRODUCTION}

The majority of phytophagous insects are specialized feeders with host plant ranges restricted to a single plant family or lower taxonomic group (Strong et al., 1984; Bernays and Chapman, 1994). Since specialization is the predominant feeding strategy of phytophagous insects, it is often considered a mechanism for speciation and generation of biological diversity (Mitter et al., 1988; Janz et al., 2006), yet the ecological and evolutionary forces that promote specialization are still poorly understood (Forister et al., 2012). The evolution of specialization is generally framed in the theory of fitness trade-offs, whereby utilization of one host in a particular environment comes at the expense of utilizing an alternative host (Futuyma and Moreno, 1988; Joshi and Thompson, 1995; Roff and Fairbairn, 2007). Through the course of natural selection, host plants that maximize insect fitness should result in optimal, specialized, insectplant associations. The ecological selection pressures promoting specializing in natural communities are multiple and varied, and include factors such as time to locate and develop on suitable hosts (Doak et al., 2006), competition for resources (Svanbäck and Bolnick, 2007), and enemy-free space (Bernays, 1989). While these contemporary ecological pressures can be important factors promoting specialization they are undoubtedly constrained to some degree by evolutionary histories that also play a role in shaping specialized insect-plant associations (Winkler and Mitter, 2008; Futuyma, 2010). Most insectplant associations share long evolutionary histories that can be traced millions of years, often to the Paleogene, 30-60 mya (Farrell, 1998; Currano et al., 2008). These long evolutionary associations have allowed phytophagous insects to adapt to the chemical and physical defensive traits of particular plant lineages and may explain the commonly observed pattern of insect host ranges being phylogenetically conserved. However, even specialized insects have limits to the concentration of chemical defenses or magnitude of physical resistance traits that they can contend with (Ali and Agrawal, 2012). Therefore, even though closely related plants often share the same defensive traits, the traits themselves can vary quantitatively, which may be more important in determining insect performance than phylogenetic relatedness.

Within the host ranges of specialized phytophagous insects, performance hierarchies are common, but the plant traits and the phylogenetic relationships of the host plants that might explain the differences in insect performance arey seldom identified. The increasing availability of comprehensive resolved phylogenies is permitting more explicit tests of hypotheses concerning the evolution of specialization, and could permit better prediction of insect host ranges, and the degree of host plant specialization (Ødegaard et al., 2005). If specialized phytophagous insects exhibit a phylogenetically conserved pattern of performance across their potential host range it would suggest that insects are tracking overall plant trait similarity to an optimal host and indicate that host plant specialization is largely governed by evolutionary history. Alternatively, if phylogeny is not a good predictor of insect performance it would suggest that specialization, although broadly bound by evolutionary history, is labile within a plant lineage, and that insects track key plant traits that may exist through convergent or parallel evolution.

Previously, the fitness of the leaf-feeding beetle, Cassida rubiginosa, was tested in relation to plant defensive traits in a phylogenetically controlled experiment with three Cirsium species (Cripps et al., 2015). The beetle is classified as an oligophagous feeder restricted to plants in the tribe Cardueae (thistles and knapweeds), but has a well-known primary host plant, Cirsium arvense (Zwölfer and Eichhorn, 1966). The herbivore defensive traits of Cardueae species have not been well characterized, but some key traits that we identified as plausibly providing defense against specialized herbivores were leaf flavonoid concentration and leaf structural defenses, which were measured as specific leaf area, and the proportion of leaf pubescence. Flavonoids are known to act as feeding deterrents or stimulants in many insect-plant systems, depending on their concentration (Harborne and Grayer, 1993; Simmonds, 2001), and are the predominant secondary chemical group in the Cardueae (Wagner, 1977; Jordon-Thaden and Louda, 2003). Similarly, leaf pubescence and toughness are well documented as herbivore resistance traits (Hanley et al., 2007), and were identified as key defensive traits reducing Cassida fitness on congeners of C. arvense (Cripps et al., 2015). This raised the question of whether or not host plant utilization within the Cardueae was driven by key defensive traits (i.e., any given Cardueae species could be equally suitable, depending on key traits), or if there was a broad phylogenetic pattern explaining host plant specialization (i.e., adaptation to an optimal host over evolutionary time, independent of defensive traits). We hypothesized that both defensive leaf traits and phylogenetic relationship would affect the survival of the beetle. To determine the component effects of plant phylogeny and defensive traits on Cassida survival we measured the phylogenetic distance of each Cardueae test species from the primary host, $C$. arvense, and measured several leaf traits (specific leaf area, leaf pubescence, flavonoid concentration, carbon and nitrogen content) that might explain differences in insect survival.

\section{MATERIALS AND METHODS}

\section{Study System}

The Cardueae is one of the largest tribes of the Compositae family comprised of approximately 2400 species in five subtribes (Susanna and Garcia-Jacas, 2007), and are considered a monophyletic group with a nearly completely resolved phylogeny (Susanna et al., 1995, 2006; Barres et al., 2013). The tribe originated during the mid-Eocene, and subtribal diversification events occurred throughout the Oligocene-Miocene period (Barres et al., 2013). The current native distribution is almost entirely in the northern hemisphere, and all of the Cardueae test species used in this study are native to Eurasia, and were introduced to New Zealand (NZ) either inadvertently, or deliberately as agricultural or ornamental plants (Webb et al., 1988). All of the inadvertently introduced Cardueae species in $\mathrm{NZ}$ are considered agricultural weeds that vary from minor to extreme economic importance (Cripps et al., 2013). The 
Cardueae plants selected for this study span three of the five subtribes and include representatives from widespread, species rich genera (e.g., Cirsium and Centaurea), and species poor genera with narrow geographic ranges (e.g., Cynara, Ptilostemon), and therefore provide a good representation of the tribe (Susanna and Garcia-Jacas, 2007; Vilatersana et al., 2010).

The tortoise beetle, Cassida rubiginosa Müller (Coleoptera: Chrysomelidae), is native to the Palearctic region where it is one of the most common insect herbivores on C. arvense (Zwölfer and Eichhorn, 1966). It was deliberately introduced to NZ in 2007 as part of the biological control program against C. arvense (Cripps et al., 2011b). Although the beetle is oligophagous, with many host plants in the Cardueae tribe, its release as a biological control agent was considered safe since there are no native Cardueae plants in NZ (Webb et al., 1988), and potential damage to economic plants (e.g., artichoke) was considered acceptable in cost-benefit analyses (Barratt et al., 2010). In its native range, at least 21 Cardueae species have been recorded as host plants, most belonging to the subtribe Carduinae (true thistles); however, the beetle shows a marked preference for C. arvense, which is considered its primary host (Zwölfer and Eichhorn, 1966). The beetle is univoltine and completes its entire life cycle (egg, 5 larval instars, pupa, and adult) on the foliage of host plants. Both adults and larvae are leaf feeders. Adults overwinter under leaf litter debris in hedge rows, or forest margins. Upon emergence in spring adults seek out host plants where they deposit their egg masses (oothecae), typically on the underside of leaves. Larvae are confined to the host plant where their eggs are laid, or adjacent overlapping shoots, but cannot move long distances along the ground to a new host plant (Tipping, 1993).

\section{Collection and Preparation of Test Plants}

All of the test plants were grown from seed, except Onopordum acanthium and Ptilostemon afer, which were collected as rosettes from natural field sites in October 2013 and directly transplanted into 12-1 pots. Seeds were either collected from the field (20092013) or purchased from a commercial supplier (King Seeds NZ Ltd.). Seeds of each species were sown on 21 August 2013. Seedlings were grown in a glasshouse at AgResearch until 17 October, when all plants were transplanted into 12-1 plastic pots, and shifted outside to the experimental location in a fenced compound area on the campus of AgResearch, Lincoln (S $43^{\circ} 38^{\prime} 20.54^{\prime \prime}$; E $172^{\circ} 28^{\prime} 28.2^{\prime \prime}$ ). The plants were arranged in a randomized complete block design with five replicate blocks (80 plants total). The plants were grown in a standard potting mix (54\% aged bark, $45 \%$ sand, $1 \%$ nutrients, by weight) containing added nutrients as Osmocote ${ }^{\circledR} 17-11-10$ (N-P-K), lime, superphosphate, sulfate of potash, and calcium nitrate. Watering of potted plants occurred four times daily (every $6 \mathrm{~h}$ ) through an automatic irrigation system.

\section{Collection and Application of Cassida}

Adult Cassida beetles were collected on 4 and 5 November 2013 from two field sites (Winton and Manapouri) in Southland NZ, where they had been released as biocontrol agents in 2007 and 2008, respectively. All adult beetles were collected from C. arvense. Adult beetles were kept in 2.2-1 ventilated plastic boxes and fed $C$. arvense shoot clippings. The beetle colony was maintained in a laboratory at AgResearch Lincoln at a constant room temperature $\left(\mathrm{ca} .20^{\circ} \mathrm{C}\right)$. Egg masses that were laid on the leaves of the clippings were removed and placed on moist filter paper in Petri dishes.

From 15 to 21 November, 12 naïve first instar larvae (hatched within $12 \mathrm{~h}$ ) were placed on new fully expanded leaves of each plant in the experiment (total of 960 larvae). Larvae were applied one block at a time ( 1 or 2 days per block). A polyester mesh bag $(50-\mathrm{cm} \times 125-\mathrm{cm})$ supported by wire struts was placed over each potted plant. At the time of beetle larvae placement, plants in the experiment were either large rosettes (biennial species), or bolting (annual species). On 27 January 2014 each plant was cut at the base and inspected in the laboratory for adult beetles. All surviving individuals were adults by this time (no other growth stages, i.e., larvae or pupae, were found), and the number of individuals per plant surviving to the adult stage was recorded. The mean temperature over the duration of the experiment (15 November to 27 January) was $16.3^{\circ} \mathrm{C}$ (range $4.4-34.8^{\circ} \mathrm{C}$ ), based on hourly temperature readings recorded in the compound area from a Tinytag ${ }^{\circledR}$ (Gemini Data Loggers Ltd) data logger.

\section{Specific Leaf Area, Leaf Pubescence, Flavonoids, Carbon, and Nitrogen Analyses}

Three leaves from each plant in the experiment (representative of the size and age of leaves that the beetles were feeding on) were taken on 3 December. A 1.0-cm diameter cork-borer was used to cut a leaf disk from each of the three leaves, avoiding the midvein of each leaf. The three disks from each replicate plant were dried in an oven at $50^{\circ} \mathrm{C}$ for $48 \mathrm{~h}$ and the dry weights were recorded to the nearest $0.1 \mathrm{mg}$. The specific leaf area (SLA) was calculated as the ratio of the leaf area to dry weight $\left(\mathrm{mm}^{2} / \mathrm{mg}\right)$ of the three disks. The remainder of the leaves were also dried and then ground in a Retsch ${ }^{\circledR}$ centrifugal mill through a $1.0-\mathrm{mm}$ sieve. After milling, tomentous leaf pubescence (tightly adhering, matted leaf hairs) was separated from the dry leaf tissue material (re-milled two or three times as necessary to separate all leaf pubescence material) and weighed separately. The proportion of tomentous pubescence of the total leaf dry weight was recorded.

Total flavonoids were determined according to Zhu et al. (2010) but volumes were adapted for 96-well microplates. Beetle larvae were still feeding on the plants at the time of sample collection ( 3 December), and it is possible that this could have induced specific flavonoids, and thereby altered concentrations relative to plants in an undamaged state. However, since herbivore induction typically triggers speciesspecific, and specialized responses (e.g., single compounds) (Karban and Baldwin, 1997) the comparisons between plant species were considered to represent constitutive flavonoid concentrations, and any induction effects were assumed to be minor. Dried leaf powder $(100 \mathrm{mg})$ was weighed into a $25-\mathrm{ml}$ screw cap bottle and extracted with $7 \mathrm{ml}$ ethanol (70\% v/v) in a sonicator bath for $30 \mathrm{~min}$. The extract was filtered (LBS 0001.090, Labserv, NZ) and an aliquot of $100 \mu \mathrm{l}$ was transferred to a 2-ml microreaction tube. For the colorimetric reaction, $100 \mu \mathrm{NaNO}_{2}$ 
$(5 \%, \mathrm{w} / \mathrm{v})$ and $100 \mu \mathrm{l} \mathrm{Al}\left(\mathrm{NO}_{3}\right)_{3}(10 \% \mathrm{w} / \mathrm{v})$ were added. After each step, the solution was vortex mixed and left to react for $6 \mathrm{~min}$. Finally, $1 \mathrm{ml} \mathrm{NaOH}(4 \% \mathrm{w} / \mathrm{v})$ and $600 \mu \mathrm{l}$ aqua dest was added to the reaction tube, which was then vortexed, and left for $15 \mathrm{~min}$. The absorbance of the extract $(175 \mu \mathrm{l})$ was read at $500 \mathrm{~nm}$ against the uncoloured sample solution blank using a spectrophotometer (Multiskan GO, Thermo Scientific, USA). Rutin (Sigma-Aldrich, Australia) was used as a standard. Each sample was measured in triplicate. The total carbon and nitrogen concentrations (\%) of the leaf samples were analyzed using an Elementar Vario-Max CN elemental analyser (Elementar Analysensysteme GmbH, Hanau, Germany).

\section{Phylogenetic Data and Analyses}

The phylogeny of the 16 Cardueae test species was pruned from a comprehensive phylogeny of the Cardueae tribe based on nuclear ribosomal DNA and chloroplast DNA markers (Barres et al., 2013). Phylogenetic distance (in millions of years, my) was calculated from the total branch lengths separating each species from $C$. arvense using the function cophenetic.phylo ( $\mathrm{R}$ package ape) (Figure 1).

Since survival was recorded as the number of Cassida adults from a group of 12 larvae that either survived or not, the percent survival values were analyzed using generalised linear models (GLMs), assuming binomial distributions through a logit link function (Faraway, 2005). The first seven GLM analyses examined if mean percent survival values were related to each of the seven explanatory variables alone (phylogenetic distance, SLA, flavonoids, percent pubescence, $C, N$, and $C / N$ ), i.e., the relationship of each individual variable to survival was examined independently from other variables. This was followed by further binomial GLM analyses that systematically examined if mean percent survival values were related to any combination of the seven explanatory variables using analysis of deviance. The sets of variables identified as statistically significant in the analysis of deviance were then compared based on their Akaike Information Criterion (AIC) values (Claeskens and Hjort, 2008).

The phylogenetic signal of all plant traits plus Cassida survival was estimated using Pagel's lambda $(\lambda)$ (Freckleton et al., 2002). Maximum likelihood estimates of the best $\lambda$ value were compared to model estimates where $\lambda$ was set at 0 (no phylogenetic signal, i.e., phylogenetic independence), or 1 (strong phylogenetic signal indicating the trait co-varies directly with shared evolutionary history).

We aimed to also test whether Cassida survival was related to plant traits while accounting for possible dependence among trait values due to shared evolutionary history. In recent years several methods have been developed to conduct phylogenetic regression analyses for continuous and binary data (for a review on methods for each type of data see Ives and Garland, 2014; and Symonds and Blomberg, 2014); however, to date there are no methods available for proportional data, such as survival percentages. Therefore, we applied arcsine square root transformations to survival proportions and performed phylogenetic generalised least squares (PGLS) regression ( $\mathrm{R}$ packages nlme, Pinheiro et al., 2013, and ape, Paradis et al., 2004). Moreover, a recent study confirms that linear models applied to transformed data provide robust statistical tests for significance over a wide range of conditions (Ives, 2015). PGLS identifies from the phylogeny the amount of expected correlation between species based on their shared evolutionary history, and weights for this in the generalized least squares regression calculation using Pagel's $\lambda$ (it should be noted that in PGLS the assumptions regarding phylogenetic non-independence refer to the residual errors of the regression model, not the traits themselves). The phylogenetic structure might affect the covariance in trait values across taxa in different ways. Therefore, we compared two types of trait evolution model for each trait: Brownian motion models (BM), in which trait covariance between any pair of taxa decreases linearly with time since their divergence (three models diverging in lambda value were compared: fixed to 1 , estimated from data, and fixed to 0); and Ornstein-Uhlenbeck models (Martins and Hansen, 1997), where the expected covariance decreases exponentially, as governed by the parameter alpha (values ranging from 0.5 to 10 were tested). PGLS was performed on all traits versus survival, each trait was first tested independently and then for all trait combinations in relation to Cassida survival.

\section{RESULTS}

Mean Cassida survival (naïve first instar to adult) on the 16 Cardueae host plants ranged from 0 to $85 \%$ (Figure 2). The survival rates of Cassida on Carduus tenuiforus, Cirsium palustre, Cirsium vulgare, and Arctium lappa were statistically equivalent to $C$. arvense. Survival rates on the remaining 11 test plant species were significantly lower than on $C$. arvense (Duncan's multiple comparison procedure, $P<0.05)$.

Of the traits measured, strong phylogenetic signal (Pagel's $\lambda$ ) was detected for Cassida survival and leaf pubescence (Table 1). The strong phylogenetic signal of Cassida survival is a good indicator that phylogeny is a good predictor of Cassida performance, and that it can be used as a surrogate for plant traits influencing fitness of this species. Although leaf pubescence showed a phylogenetic signal (Table 1) it did not contribute significantly to Cassida survival.

Based on the AIC values of significant GLMs, the most appropriate single-variable model predicting Cassida survival was phylogenetic distance, followed by SLA (Table 2). Survival of Cassida decreased with increasing phylogenetic distance from the primary host, C. arvense (Figure 2; Table 2), and this relationship remained significant after controlling for phylogenetic non-independence in the residuals (PGLS), indicating that phylogenetic distance itself (i.e., total branch length separation from $C$. arvense) is a good proxy for survival rates. Survival of Cassida increased with increasing SLA (Figure 3; Table 2), and this also remained significant after correcting for phylogenetic non-independence. From the single-variable GLMs, phylogenetic distance explained $58.4 \%$ of the variation in survival, and SLA explained $50.1 \%$ (i.e., the model correctly classified these percentages of individuals into survival/death groups). Similarly, based on the AIC values of significant multi-variable GLMs the most appropriate model was that of phylogenetic distance combined with SLA (Table 2). The 


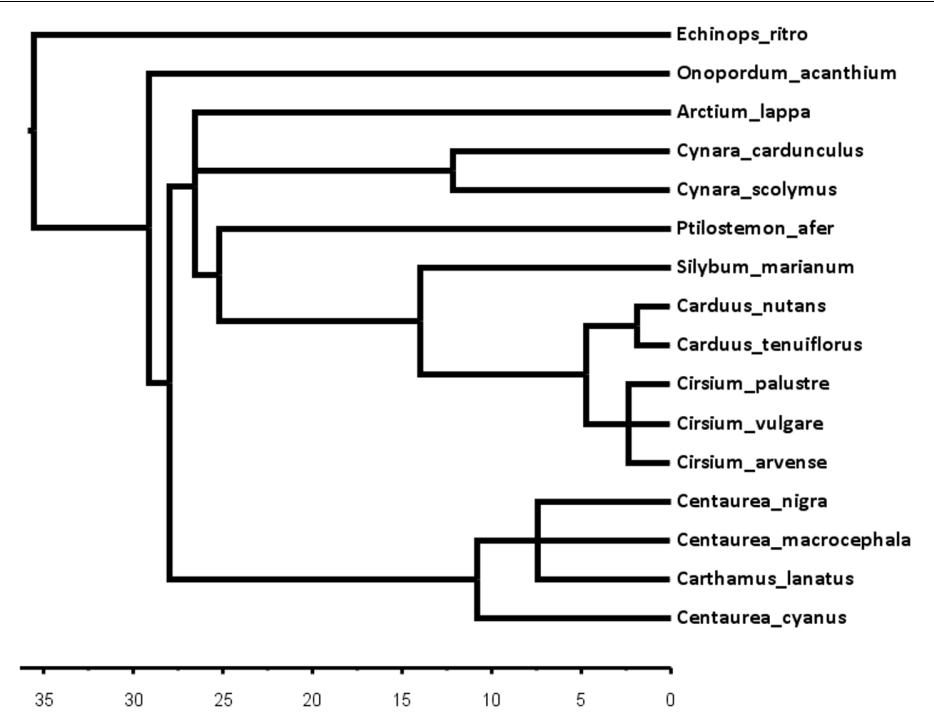

FIGURE 1 | Chronogram of the 16 Cardueae test species pruned from a comprehensive phylogeny of the tribe (Barres et al., 2013). Branch lengths depict phylogenetic distances in millions of years (my).

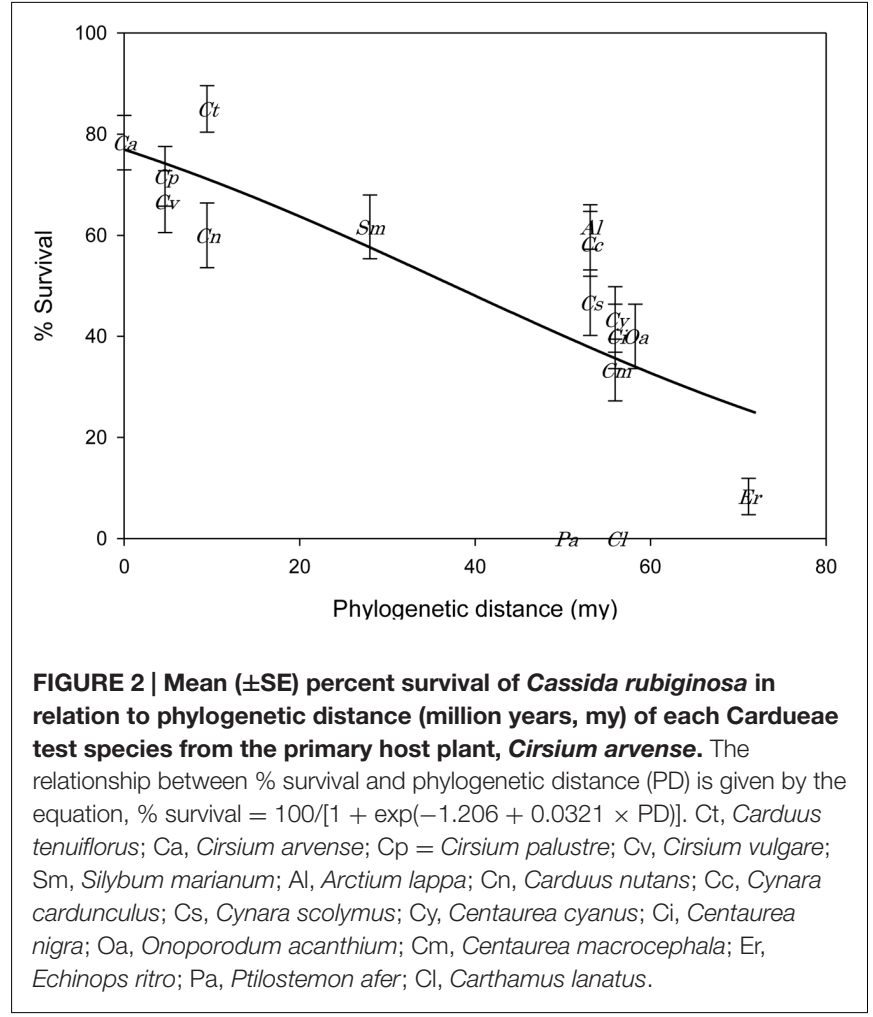

GLM of phylogenetic distance + SLA explained $66.7 \%$ of the variation in Cassida survival. None of the other traits that were measured significantly explained survival of Cassida across the 16 test plants. In particular, total flavonoid concentrations did not explain Cassida survival $(P=0.413)$. The plant species with the highest survival rate $(85 \%, C$. tenuiflorus), and the species with the lowest survival rates $(0 \%, P$. afer and C. lanatus), had similarly low flavonoid concentrations (mean flavonoid concentrations for C. tenuifolorus $=0.2 \mathrm{mg} / \mathrm{gDW} ;$ P. afer $=0.2 \mathrm{mg} / \mathrm{gDW}$; and C. lanatus $=0.6 \mathrm{mg} / \mathrm{gDW}$ ) (Figure 4).

In PGLS analyses, the most appropriate single-variable model predicting Cassida survival was SLA, followed by PD (phylogenetic distance), and C content (Table 3). According to the AIC values of significant multi-variable PGLS models, the most appropriate models are SLA + Percent pubescence, SLA + N content, SLA + flavonoids, and SLA + C:N ratio. All these models obtained very similar AIC values (Table 3 ). Only one of these four models (SLA $+\mathrm{N}$ ) was significantly improved (according to likelihood ratio-test) by the addition of other variables: SLA $+\mathrm{N}+\mathrm{PD}+\mathrm{C}: \mathrm{N}+$ Percent pubescence (Table 3). In this more complex model, survival decreases with phylogenetic distance, and increases with SLA, N content, $\mathrm{C}: \mathrm{N}$, and pubescence, although the final contributing variable (pubescence) was not statistically significant on its own.

\section{DISCUSSION}

In accordance with our hypothesis, this study demonstrated that the survival of Cassida decreased with increasing phylogenetic distance from the primary host plant, C. arvense. This indicates that specialization is a conserved character, and that insect host range, to a large degree is constrained by evolutionary history. While the phylogenetically conserved pattern of insect performance has been long recognized (Wapshere, 1974), the novelty of the present work is that is uses a quantitative measure of evolutionary separation between hosts to predict insect herbivore performance across its host range (Pearse and Hipp, 2009; Rasmann and Agrawal, 2011). Phylogenetic distance is in essence a composite measure of trait similarity among the Cardueae test species, and is ultimately a good 
predictor of Cassida survival. However, the particular traits (chemical/physical) that account for the phylogenetic effect are still uncertain.

The only trait measured that clearly offered some explanatory value for the survival of Cassida across the 16 Cardueae test plants was SLA. This trait was independent of phylogeny, and when combined with phylogenetic distance from $C$. arvense was the best model explaining Cassida survival. This also conferred with our hypothesis that defensive traits, in addition to phylogenetic relationship, affect insect survival. Plant species with high SLA have many features conducive to herbivore feeding, such as lower dry matter, faster growth rate, and reduced leaf toughness (Salgado-Luarte and Gianoli, 2010), and this trait was shown to be an important factor explaining survival of Cassida on plants congeneric to C. arvense (Cripps et al., 2015). The only plant trait found to have a clear phylogenetic signal was leaf pubescence, but this trait was not related to Cassida survival. The fact that leaf pubescence showed a phylogenetic signal is likely an artifact of low sample size since this trait is common in plant species across the Cardueae subtribes (Susanna and Garcia-Jacas, 2007), and is therefore unlikely to be part of the underlying phylogenetic explanation for Cassida survival. Leaf pubescence is known to provide resistance against most types of insect herbivores, including both generalist and specialist feeders (Hanley et al., 2007), and previously trichome density was found to be an important factor determining survival rates of Cassida on plants congeneric to C. arvense (Cripps et al., 2015). In the

TABLE 1 | Phylogenetic signal (Pagel's $\lambda$ ) for plant traits and survival of Cassida rubiginosa.

\begin{tabular}{|c|c|c|c|}
\hline Trait & $\lambda_{\text {estimated }}$ & $\begin{array}{c}\text { Significantly } \\
\text { different from } \\
\lambda=0\end{array}$ & $\begin{array}{c}\text { Significantly } \\
\text { different from } \\
\lambda=1\end{array}$ \\
\hline Cassida survival (\%) & 0.85 & 0.01 & 0.14 \\
\hline $\begin{array}{l}\text { Leaf pubescence } \\
\text { (\%) }\end{array}$ & 0.95 & 0.01 & 0.44 \\
\hline $\begin{array}{l}\text { Flavonoid } \\
\text { concentration } \\
(\mathrm{mg} / \mathrm{g})\end{array}$ & 0 & 1 & $2.97 \times 10^{-4}$ \\
\hline $\begin{array}{l}\text { Specific leaf area } \\
\left(\mathrm{mm}^{2} / \mathrm{mg}\right)\end{array}$ & 0 & 1 & $2.97 \times 10^{-4}$ \\
\hline C (\%) & 0 & 1 & $1.36 \times 10^{-5}$ \\
\hline$N(\%)$ & 0 & 1 & $1.48 \times 10^{-3}$ \\
\hline C:N ratio & 0 & 1 & $6.40 \times 10^{-3}$ \\
\hline
\end{tabular}

Values of $\lambda$ close to 1 indicate a strong phylogenetic signal (resulting from shared evolutionary history), whereas values close to 0 indicate that phylogenetic signal is weak or null.



FIGURE 3 | Mean ( \pm SE) percent survival of Cassida rubiginosa in relation to specific leaf area of the 16 Cardueae test species. The relationship between \% survival and specific leaf area (SLA) is given by the equation, \% survival $=100 /[1+\exp (1.770-0.0670 \times$ SLA) $]$. Ct, Carduus tenuiflorus; $\mathrm{Ca}$, Cirsium arvense; $\mathrm{Cp}$, Cirsium palustre; Cv, Cirsium vulgare; Sm, Silybum marianum; Al, Arctium lappa; Cn, Carduus nutans; Cc, Cynara cardunculus; Cs, Cynara scolymus; Cy, Centaurea cyanus; Ci, Centaurea nigra; Oa, Onoporodum acanthium; Cm, Centaurea macrocephala; Er, Echinops ritro; $\mathrm{Pa}$, Ptilostemon afer; $\mathrm{Cl}$, Carthamus lanatus.

present study, leaf pubescence was measured as a proportion of total leaf dry weight and specific pubescence structures that might differently affect Cassida survival were not distinguished. On Cirsium species, where the density of pubescence is important for Cassida survival, leaves are villose below and hirsute-hispidule above, and both types of hairs can create a barrier to the leaf surface. However, some other Cardueae species (e.g., Cynara and Onopordum spp.) have a relatively high proportion of leaf pubescence, but it is tightly adhering tomentous pubescence that does not appear to inhibit access to the leaf surface, and therefore does not affect Cassida survival.

Total flavonoid concentration did not show a phylogenetic signal, and did not explain Cassida survival. Interestingly, the host plant with the highest survival rate (85\%, C. tenuiflorus) had a similarly low flavonoid concentration as the two nonhost species ( $P$. afer and $C$. lanatus). From other studies, there is mixed evidence with regard to the importance of flavonoids on insect performance, with inhibitory effects on some herbivore species, but no effects on others (Simmonds, 2001), regardless of being a generalist or specialist (Bi et al., 1997). While total flavonoids did not explain Cassida survival in

TABLE 2 | Plant traits predicting survival of Cassida rubiginosa resulting from the binomial generalised linear model (GLM) analyses.

\begin{tabular}{|c|c|c|c|}
\hline GLM & Relationship to survival (\%) & Significance & AIC \\
\hline Phylogenetic distance (PD) & $100 /[1+\exp (-1.206+0.0321 \times P D)]$ & $<0.001$ & 1158 \\
\hline Specific leaf area (SLA) & $100 /[1+\exp (1.770-0.0670 \times$ SLA $)]$ & $<0.001$ & 1216 \\
\hline$P D+S L A$ & $100 /[1+\exp (0.973+0.0404 \times \mathrm{PD}-0.0978 \times \mathrm{SLA})]$ & $<0.001$ & 1105 \\
\hline
\end{tabular}

Lower Akaike Information Criterion (AIC) values indicate a closer fit to the data. 


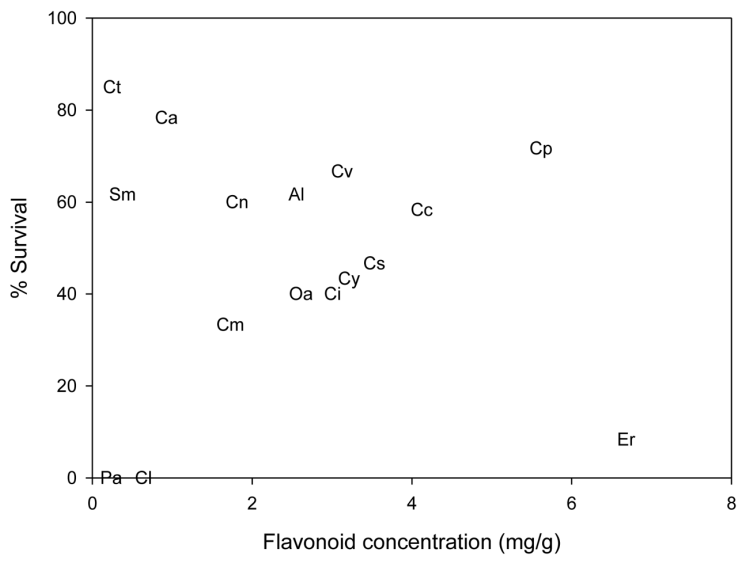

FIGURE 4 | Mean flavonoid concentration and percent survival of Cassida rubiginosa on 16 Cardueae test species. The relationship between \% survival and flavonoid concentration is not significant. Ct, Carduus tenuiflorus; Ca, Cirsium arvense; Cp, Cirsium palustre; Cv, Cirsium vulgare; Sm, Silybum marianum; Al, Arctium lappa; Cn, Carduus nutans; Cc, Cynara cardunculus; Cs, Cynara scolymus; Cy, Centaurea cyanus; Ci, Centaurea nigra; Oa, Onoporodum acanthium; Cm, Centaurea macrocephala; Er, Echinops ritro; Pa, Ptilostemon afer; $\mathrm{Cl}$, Carthamus lanatus.

this study it is likely that the specific flavonoid composition is important. In a related study, Cassida was shown to be tolerant to double the concentration of flavonoids on plants congeneric to $C$. arvense, which suggested that Cassida might be adapted to specific flavonoids that were common to plants closely related to C. arvense (Cripps et al., 2015). Although flavonoids are the predominant group of secondary chemicals in the Cardueae, other chemicals such as terpenoids and alkaloids have also been identified from Cardueae species, and could also play a role in resistance to herbivores (Wagner, 1977). Cardueae species share many secondary chemical compounds, but also have unique profiles, and it is possible that the underlying phylogenetic effect is explained by overall chemical similarity to the primary host (Jordon-Thaden and Louda, 2003). Much attention is often given to the role of defensive secondary chemistry; however, it is also possible that non-defensive chemicals might explain the phylogenetic effect on Cassida performance (Jermy, 1993). Insects often require sufficient stimuli for host recognition and sustained feeding that can be obtained through chemical attributes of the leaf surface, such as volatile organic compounds, epicuticular waxes, and primary metabolite exudates such as sugars and amino acids (Müller and Riederer, 2005).

Both phylogenetic relatedness and putative resistance traits independent of phylogeny (i.e., low SLA) contributed to the survival of Cassida, a conclusion also reached by similar studies (Becerra, 1997; Rasmann and Agrawal, 2011; Gilbert et al., 2015). These data indicate that specialization of Cassida on C. arvense has likely arisen through a combination of the beetle tracking phylogenetically conserved traits and responding to plant resistance characters that impose selection pressures for or against host utilization. This is in contrast to the conclusion reached by Slotta et al. (2012) who suggested that specialized herbivores on Cirsium and Carduus species do not follow a phylogenetic pattern, and that phylogeny does not predict host specificity. However, it should be noted that their conclusion was based only on literature records of known host associations and therefore the insect-plant associations for the bulk of species in their phylogeny are uncertain. Furthermore, the fact that a plant is recorded as a host does not mean it is an equivalent host in terms of insect fitness.

The potential to utilize other, more distantly related Cardueae plants, raises the question of what conditions might promote shifts in primary host use, and whether or not these could be sustained. The question is particularly pertinent in novel ranges such as NZ, where altered selection pressures are likely to exist, and may result in changes in the pattern of host plant use. Resistance characters might act to channel host plant selection and utilization without eliminating the innate ability of the insect to utilize other host plants, but whether or not resistance traits have evolved in response to herbivory is unclear. Traits such as low SLA (thick, tough leaves) and leaf pubescence are typically considered adaptations to xeric environments that primarily function to regulate temperature and conserve water (Johnson, 1975; Niinemets, 2001), and therefore these traits

TABLE 3 | Plant traits predicting survival of Cassida rubiginosa resulting from phylogenetic least squares regression (PGLS) to account for possible dependence among trait values due to shared evolutionary history.

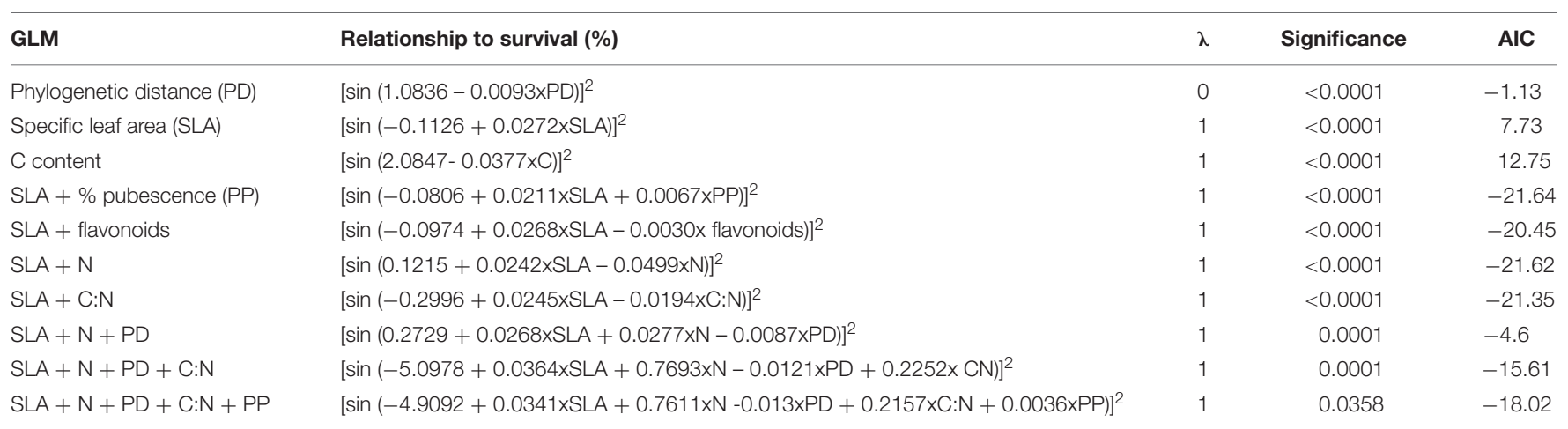

Lower Akaike Information Criterion (AIC) values indicate a closer fit to the data. Survival values were arc-sine square-root transformed. Phylogenetic signal associated with the regression was estimated with $\lambda$ (values near 1 indicate strong phylogenetic signal of the residuals, values near 0 indicate null or weak phylogenetic signal). 
could be retained even in the absence of herbivory. However, if Cassida herbivory has fitness consequences for the plant, this could impose selection pressure for increased defensive traits (resistance and/or tolerance). This would depend on the degree of variation in defensive traits of thistles in NZ, but could result in reduced performance of Cassida over time. In the novel range of NZ, most Cardueae plants have experienced over a century of release from specialized insect herbivores (Cripps et al., 2011a), which may have allowed for evolution of reduced defenses (Bossdorf et al., 2005) that could, at least temporarily, enable increased fitness in Cassida on C. arvense and other Cardueae hosts.

Part of the reason for successful classical biological control is that insect biocontrol agents are released in novel, relatively benign environments, compared to their native ranges, and can achieve greater population numbers (Myers, 1987). The primary reason for this is release from the regulating influence of specialized predators and parasitoids. In NZ, Cassida experiences relaxed natural enemy pressure that allows population numbers of the beetle to increase far greater than observed in the native range (Cripps, 2013). Large numbers of the beetle might result in competition for the food resource and promote selection for alternative hosts, where competition is reduced, and survival rates are greater. Changes in the relative abundance of host plants due to successful biological control of one species, or land management changes that favor particular species, could also promote a shift in primary host plant utilization. Even with fitness trade-offs on alternative hosts (e.g., due to resistance traits), a more abundant resource might contribute more to beetle population numbers, and therefore selection could act to favor the more abundant plant (Futuyma, 2010). In fact, regional differences in Cardueae species abundance are thought to have led to biotype development of specialized capitulumfeeding insects, and was suggested as a mechanism for sympatric or parapatric speciation over evolutionary time (Zwölfer and Romstöck-Völkl, 1991). Given that other Cardueae plants are suitable hosts for Cassida, and four species other than the primary host were determined to be equivalent hosts for larval survival, there is potential for an altered pattern of host use in NZ (Van

\section{REFERENCES}

Ali, J. G., and Agrawal, A. A. (2012). Specialist versus generalist insect herbivores and plant defense. Trends Plant Sci. 17, 293-302. doi: 10.1016/j.tplants.2012.02.006

Barratt, B. I. P., Howarth, F. G., Withers, T. M., Kean, J. M., and Ridley, G. S. (2010). Progress in risk assessment for classical biological control. Biol. Control 52, 245-254. doi: 10.1016/j.biocontrol.2009.02.012

Barres, L., Sanmartín, I., Anderson, C. L., Susanna, A., Buerki, S., GalbanyCasals, M., et al. (2013). Reconstructing the evolution and biogeographic history of tribe Cardueae (Compositae). Am. J. Bot. 100, 867-882. doi: 10.3732/ajb. 1200058

Becerra, J. X. (1997). Insects on plants: macroevolutionary chemical trends in host use. Science 276, 253-256. doi: 10.1126/science.276.5310.253

Bernays, E. (1989). Host range in phytophagous insects: the potential role of generalist predators. Evol. Ecol. 3, 299-311. doi: 10.1007/BF02285261

Bernays, E. A., and Chapman, R. F. (1994). Host-Plant Selection by Phytophagous Insects. London: Chapman \& Hall.
Klinken and Edwards, 2002). This will largely depend on the ecological selection pressures acting on host use, and how these are balanced against possible fitness consequences of using an alternative host. Determining the ecological selection pressures (e.g., enemy-free space) that influence the realized host range of Cassida in NZ will be the subject of future investigation, and will reveal the potential for contemporary evolution in novel environments, and also aid in predicting the success of an oligophagous biocontrol agent for controlling multiple thistle weeds.

\section{AUTHOR CONTRIBUTIONS}

The study was conceived by MC, MR, and GB. The experimental work was carried out by MC, SJ, and MR. Phylogenetic data was provided AS, and analyses were carried out by CR and CvK. MC wrote the manuscript with contributions from all authors.

\section{ACKNOWLEDGMENTS}

We thank Randall Milne (Environment Southland) and Jesse Bythell (Biosis) for assistance with collections of Cassida rubiginosa. We thank Trevor James (AgResearch) for providing seeds of several species, Miles Giller (QEII National Trust) for assistance with collecting Ptilostemon afer, and Rob McCaw (Environment Canterbury) for assistance with collecting Onopordum acanthium. We thank Anthony Ives (University of Wisconsin) for advice concerning phylogenetic least squares regression. This research was funded by the New Zealand Ministry of Business, Innovation, and Employment through AgResearch core funding of pasture weeds research. Funding of the flavonoid analyses was supported by the Bio-Protection Research Centre, Lincoln University. The Australasian Congress of Grassland Invertebrate Ecology provided financial assistance for open access publication fees. This research was published as part of a series of articles from the ninth Australasian Congress of Grassland Invertebrate Ecology.

Bi, J., Felton, G., Murphy, J., Howles, P., Dixon, R., and Lamb, C. (1997). Do plant phenolics confer resistance to specialist and generalist insect herbivores? J. Agric. Food Chem. 45, 4500-4504. doi: 10.1021/jf970555m

Bossdorf, O., Auge, H., Lafuma, L., Rogers, W. E., Siemann, E., and Prati, D. (2005). Phenotypic and genetic differentiation between native and introduced plant populations. Oecologia 144, 1-11. doi: 10.1007/s00442-005-0070-Z

Claeskens, G., and Hjort, N. L. (2008). Model Selection and Model Averaging. Cambridge: Cambridge University Press.

Cripps, M. G. (2013). Observations on the thistle-feeding tortoise beetle, Cassida rubiginosa (Coleoptera: Chrysomelidae). Weta 45, 5-13.

Cripps, M. G., Bourdôt, G. W., and Fowler, S. V. (2013). Sleeper thistles in New Zealand: status and biocontrol potential. N. Z. Plant Prot. 66, 99-104.

Cripps, M. G., Bourdôt, G. W., Saville, D. J., Hinz, H. L., Fowler, S. V., and Edwards, G. R. (2011a). Influence of insects and fungal pathogens on individual and population parameters of Cirsium arvense in its native and introduced ranges. Biol. Invasions 13, 2739-2754. doi: 10.1007/s10530-011-9944-7

Cripps, M. G., Gassmann, A., Fowler, S. V., Bourdôt, G. W., McClay, A. S., and Edwards, G. R. (2011b). Classical biological control of Cirsium arvense: 
lessons from the past. Biol. Control 57, 165-174. doi: 10.1016/j.biocontrol.2011. 03.011

Cripps, M. G., Jackman, S. D., Rostas, M., Van Koten, C., and Bourdôt, G. W. (2015). Leaf traits of congeneric host plants explain differences in performance of a specialist herbivore. Ecol. Entomol. 40, 237-246. doi: 10.1111/een. 12180

Currano, E. D., Wilf, P., Wing, S. L., Labandeira, C. C., Lovelock, E. C., and Royer, D. L. (2008). Sharply increased insect herbivory during the PaleoceneEocene thermal maximum. Proc. Natl. Acad. Sci. U.S.A. 105, 1960-1964. doi: 10.1073/pnas.0708646105

Doak, P., Kareiva, P., and Kingsolver, J. (2006). Fitness consequences of choosy oviposition for a time-limited butterfly. Ecology 87, 395-408. doi: 10.1890/050647

Faraway, J. J. (2005). Extending the Linear Model with R: Generalized Linear, Mixed Effects and Nonparametric Regression Models. Boca Raton, FL: CRC press.

Farrell, B. D. (1998). Inordinate fondness explained: why are there so many beetles? Science 281, 555-559.

Forister, M., Dyer, L., Singer, M., Stireman, I. I. I. J., and Lill, J. (2012). Revisiting the evolution of ecological specialization, with emphasis on insect-plant interactions. Ecology 93, 981-991. doi: 10.1890/11-0650.1

Freckleton, R. P., Harvey, P. H., and Pagel, M. (2002). Phylogenetic analysis and comparative data: a test and review of evidence. Am. Nat. 160, 712-726. doi: $10.1086 / 343873$

Futuyma, D. J. (2010). Evolutionary constraint and ecological consequences. Evolution 64, 1865-1884. doi: 10.1111/j.1558-5646.2010.00960.x

Futuyma, D. J., and Moreno, G. (1988). The evolution of ecological specialization. Ann. Rev. Ecol. Syst. 19, 207-233. doi: 10.1146/annurev.es.19.110188. 001231

Gilbert, G. S., Briggs, H. M., and Magarey, R. (2015). The impact of plant enemies shows a phylogenetic signal. PLOS ONE 10:e0123758. doi: 10.1371/journal.pone. 0123758

Hanley, M. E., Lamont, B. B., Fairbanks, M. M., and Rafferty, C. M. (2007). Plant structural traits and their role in anti-herbivore defence. Perspect. Plant Ecol. Evol. Syst. 8, 157-178. doi: 10.1016/j.ppees.2007.01.001

Harborne, J. B., and Grayer, R. J. (1993). "Flavonoids and insects," in The Flavonoids: Advances in Research Since 1986, ed. J. B. Harborne (London: Chapman \& Hall), 589-618.

Ives, A. R. (2015). For testing the significance of regression coefficients, go ahead and log-transform count data. Methods Ecol. Evol. 6, 828-835. doi: 10.1111/2041-210X.12386

Ives, A. R., and Garland, J. T. (2014). Phylogenetic Regression for Binary Dependent Variables. Modern Phylogenetic Comparative Methods and Their Application in Evolutionary Biology. Berlin-Heidelberg: Springer, 231-261.

Janz, N., Nylin, S., and Wahlberg, N. (2006). Diversity begets diversity: host expansions and the diversification of plant-feeding insects. BMC Evol. Biol. 6:4. doi: 10.1186/1471-2148-6-4

Jermy, T. (1993). Evolution of insect-plant relationships-a devil's advocate approach. Entomol. Exp. Appl. 66, 3-12. doi: 10.1111/j.1570-7458. 1993.tb00686.x

Johnson, H. B. (1975). Plant pubescence: an ecological perspective. Bot. Rev. 41, 233-258. doi: 10.1007/BF02860838

Jordon-Thaden, I. E., and Louda, S. M. (2003). Chemistry of cirsium and carduus: a role in ecological risk assessment for biological control of weeds? Biochem. Syst. Ecol. 31, 1353-1396. doi: 10.1016/S0305-1978(03)00130-3

Joshi, A., and Thompson, J. N. (1995). Trade-offs and the evolution of host specialization. Evol. Ecol. 9, 82-92. doi: 10.1007/BF01237699

Karban, R., and Baldwin, I. T. (1997). Induced Responses to Herbivory. Chicago, IL: University of Chicago Press.

Martins, E. P., and Hansen, T. F. (1997). Phylogenies and the comparative method: a general approach to incorporating phylogenetic information into the analysis of interspecific data. Am. Nat. 149, 646-667. doi: 10.1086/ 286013

Mitter, C., Farrell, B., and Wiegmann, B. (1988). The phylogenetic study of adaptive zones: has phytophagy promoted insect diversification? Am. Nat. 132, 107-128. doi: $10.1086 / 284840$

Müller, C., and Riederer, M. (2005). Plant surface properties in chemical ecology. J. Chem. Ecol. 31, 2621-2651. doi: 10.1007/s10886-0057617-7
Myers, J. H. (1987). "Population outbreaks of introduced insects: lessons from the biological control of weeds," in Insect Outbreaks, ed. P. Barbosa (San Diego: Academic Press), 173-193.

Niinemets, Ü. (2001). Global-Scale climatic controls of leaf dry mass per area, density, and thickness in trees and shrubs. Ecology 82, 453-469. doi: 10.1890/0012-9658(2001)082[0453:GSCCOL]2.0.CO;2

Ødegaard, F., Diserud, O. H., and Østbye, K. (2005). The importance of plant relatedness for host utilization among phytophagous insects. Ecol. Lett. 8, 612-617. doi: 10.1111/j.1461-0248.2005.00758.x

Paradis, E., Claude, J., and Strimmer, K. (2004). APE: analyses of phylogenetics and evolution in R language. Bioinformatics 20, 289-290. doi: 10.1093/bioinformatics/btg412

Pearse, I. S., and Hipp, A. L. (2009). Phylogenetic and trait similarity to a native species predict herbivory on non-native oaks. Proc. Natl. Acad. Sci. U.S.A. 106, 18097-18102. doi: 10.1073/pnas.0904867106

Pinheiro, J., Bates, D., DebRoy, S., and Sarkar, D. (2013). nlme: Linear and Nonlinear Mixed Effects Models. R Package Version 3.1-111.

Rasmann, S., and Agrawal, A. A. (2011). Evolution of specialization: a phylogenetic study of host range in the red milkweed beetle (Tetraopes tetraophthalmus). Am. Nat. 177, 728-737. doi: 10.1086/659948

Roff, D., and Fairbairn, D. (2007). The evolution of trade-offs: where are we? J. Evol. Biol. 20, 433-447. doi: 10.1111/j.1420-9101.2006.01255.x

Salgado-Luarte, C., and Gianoli, E. (2010). Herbivory on temperate rainforest seedlings in sun and shade: resistance, tolerance and habitat distribution. PLoS ONE 5:e11460. doi: 10.1371/journal.pone.0011460

Simmonds, M. S. J. (2001). Importance of flavonoids in insect-plant interactions: feeding and oviposition. Phytochemistry 56, 245-252. doi: 10.1016/S00319422(00)00453-2

Slotta, T. A. B., Horvath, D. P., and Foley, M. E. (2012). Phylogeny of Cirsium spp. in North America: host specificity does not follow phylogeny. Plants 1, 61-73. doi: 10.3390/plants1020061

Strong, D. R., Lawton, J. H., and Southwood, R. (1984). Insects on Plants: Community Patterns and Mechansims. Boston, MA: Blackwell Scientific Publications.

Susanna, A., and Garcia-Jacas, N. (2007). “Tribe Cardueae Cass. (1819)," in The Families and Genera of Vascular Plants, ed. K. Kubitzki (Berlin: SpringerVerlag), 23-147.

Susanna, A., Garcia-Jacas, N., Hidalgo, O., Vilatersana, R., and Garnatje, T. (2006). The Cardueae (Compositae) revisited: insights from ITS, trnL-trnF, and matK nuclear and choloroplast DNA analysis. Ann. Mo. Bot. Gard. 93, 150-171. doi: 10.3417/0026-6493(2006)93[150:TCCRIF]2.0.CO;2

Susanna, A., Garcia-Jacas, N., Soltis, D. E., and Soltis, P. S. (1995). Phylogenetic relationships in tribe cardueae (Asteraceae) based on ITS sequences. Am. J. Bot. 82, 1056-1068. doi: 10.2307/2446236

Svanbäck, R., and Bolnick, D. I. (2007). Intraspecific competition drives increased resource use diversity within a natural population. Proc. R. Soc. Lond. B Biol. Sci. 274, 839-844. doi: 10.1098/rspb.2006.0198

Symonds, M. R., and Blomberg, S. P. (2014). A Primer on Phylogenetic Generalised Least Squares. Modern Phylogenetic Comparative Methods and their Application in Evolutionary Biology. . Berlin-Heidelberg: Springer, $105-130$.

Tipping, P. W. (1993). Field studies with Cassida rubiginosa (Coleoptera: Chrysomelidae) in Canada thistle. Environ. Entomol. 22, 1402-1407. doi: 10.1093/ee/22.6.1402

Van Klinken, R. D., and Edwards, O. R. (2002). Is host-specificity of weed biological control agents likely to evolve rapidly following establishment? Ecol. Lett. 5, 590-596. doi: 10.1046/j.1461-0248.2002.00343.x

Vilatersana, R., Garcia-Jacas, N., Garnatje, T., Molero, J., Sonnante, G., and Susanna, A. (2010). Molecular phylogeny of the genus Ptilostemon (Compositae: Cardueae) and Its relationships with Cynara and Lamyropsis. Syst. Bot. 35, 907-917. doi: 10.1600/036364410X5 39952

Wagner, H. (1977). "Cynareae - chemical review," in The Biology and Chemistry of the Compositae, eds V. H. Heywood, J. B. Harborne, and B. L. Turner (London: Academic Press), 1017-1038.

Wapshere, A. J. (1974). A strategy for evaluating the safety of organisms for biological weed control. Ann. Appl. Biol. 77, 201-211. doi: 10.1111/j.17447348.1974.tb06886.x 
Webb, C. J., Sykes, W. R., and Garnock-Jones, P. J. (1988). Flora of New Zealand. Christchurch: DSIR, Botany Division.

Winkler, I. S., and Mitter, C. (2008). "The phylogenetic dimension of insectplant interactions: a review of recent evidence," in The Evolutionary Biology of Herbivorous Insects: Specialization, Speciation, and Radiation, ed. K. J. Tilmon (Berkeley: University of California Press), 240-263.

Zhu, H., Wang, Y., Liu, Y., Xia, Y., and Tang, T. (2010). Analysis of flavonoids in Portulaca oleracea L. by UV-vis spectrophotometry with comparative study on different extraction technologies. Food Anal. Methods 3, 90-97. doi: 10.1007/s12161-009-9091-2

Zwölfer, H., and Eichhorn, O. (1966). The host ranges of Cassida spp. (Col. Chrysomelidae) attacking Cynareae (Compositae) in Europe. Z. für Entomol. $58,384-397$.

Zwölfer, H., and Romstöck-Völkl, M. (1991). "Biotypes and the evolution of niches in phytophagous insects on Cardueae hosts," in Plant-Animal Interactions:
Evolutionary Ecology in Tropical and Temperate Regions, eds P. W. Price, T. M. Lewinsohn, G. W. Fernandes, and W. W. Benson (New York, NY: John Wiley \& Sons, Inc.), 487-507.

Conflict of Interest Statement: The authors declare that the research was conducted in the absence of any commercial or financial relationships that could be construed as a potential conflict of interest.

Copyright (c) 2016 Cripps, Jackman, Roquet, van Koten, Rostás, Bourdôt and Susanna. This is an open-access article distributed under the terms of the Creative Commons Attribution License (CC BY). The use, distribution or reproduction in other forums is permitted, provided the original author(s) or licensor are credited and that the original publication in this journal is cited, in accordance with accepted academic practice. No use, distribution or reproduction is permitted which does not comply with these terms. 